\title{
LABORATORY EVALUATION OF PRE-POLYMERIZED DENTURE BASE MATERIAL USED FOR CAD/CAM COMPLETE DENTURE MANUFACTURING
}

\author{
Yusra M. Saad ${ }^{1} B D s$, Ahmed M. Abdelhamid ${ }^{2} P h D$, Sonia M. ElShabrawy ${ }^{3} P h D$.
}

\begin{abstract}
INTRODUCTION: CAD/CAM denture base materials are milled from pre-polymerized pucks of resin that are highly condensed. So, they provide no polymerization shrinkage eliminating its subsequent disadvantages. This technology offered improved fit, strength properties and more bio-hygienic denture bases compared with conventional processing of the denture base material.

OBJECTIVES: The aim of the study was to evaluate the physico-mechanical properties of CAD/CAM denture base material and the effect of thermo-cycling on it compared with the conventional one.

MATERIALS AND METHODS: The study was conducted on two parallel groups, divided according to the denture material used. Group (1) conventional PMMA (control group), group (II) CAD/CAM PMMA (study group) of 40 specimens each (16 for impact strength, 16 for flexural strength, 8 for surface roughness and grinded powder form both materials for residual monomer test). Each group was divided into 2 sub-groups: (A) No thermo-cycling and (B) Thermo-cycling, then subjected to 4 different tests, impact strength, flexural strength, surface roughness and residual monomer tests. Data were collected, tabulated and statistically analyzed. Significance level was set at $5 \%$. Bar charts were used for graphical presentations.

RESULTS: Our study revealed a highly statistically significant decrease in residual monomer of CAD/CAM PMMA material in both conditions before and after thermo-cycling when compared to conventional PMMA material, which therefore leads to enhanced impact strength and significantly reduced surface roughness after heat treatment. On the other hand, also a highly significant reduction of its flexural strength after thermocycling has been observed.

CONCLUSIONS: CAD/CAM dentures with lower amount of methacrylate monomer exhibit more favourable physico-mechanical properties and they have a long-term biocompatibility even with thermal changes making them a more satisfactory as a denture base material for edentulous patients.
\end{abstract}

KEYWORDS: CAD/CAM, Flexural strength, Impact strength, PMMA, Residual monomer, Surface roughness.

1- BDS and Demonstrator, Removable prosthodontic department, Faculty of Dentistry, Benghazi University, Libya.

2- Professor of Prosthodontics, Faculty of Dentistry, Alexandria University, Egypt.

3- Professor and Head of Biomaterial, Faculty of Dentistry, Alexandria University, Egypt.

Corresponding author:

E-mail: yusra.elfaidy@hotmail.com

\section{INTRODUCTION}

Loss of teeth is a matter of great concern to a majority of people and their replacement by artificial substitutes such as denture fabricated from acrylic resin, is vital to the continuance of normal life. Denture base acts as an intermediary between teeth and jaws, it must transfer all or part of masticatory forces to the sub-adjacent tissues (1).

Poly methyl methacrylate (PMMA) was first introduced in 1937 and is currently the material of choice for the fabrication of removable partial denture and complete denture bases. It is still used, because of its ease of manipulation, proper fit, dimensional stability and superior esthetics (2).

Conversely some disadvantages have also been described, such as residual monomer allergy, polymerization shrinkage, low fatigue strength and brittleness on impact (3). These disadvantages regularly lead to denture fracture during chewing or when the denture is dropped out of the patient's hand.

Continuous efforts to increase the material strength to decrease the risk of denture fractures can be mentioned as; reinforcement of denture bases by adding filling materials, changing the chemistry of the denture base polymer by copolymerization or cross-linking of resin materials, manufacturing new materials with high resistance to fracture and incorporation of new techniques to the dental field (4).

In an attempt to overcome some of these disadvantages, Computer-Aided Design (CAD) / ComputerAided Manufacturing (CAM) technologies have been applied in the field of prosthodontics since the 1980s (5).

CAD/CAM technology was introduced to provide a denture base which is fabricated by machining. Therefore, polymerization shrinkage of the resin is eliminated also the fit of denture base is greater than conventionally fabricated one (6).

The material appears to contain less residual monomer to be more hydrophobic than the conventionally processed one. Subsequently, this results in a more biohygienic denture. Because of freedom from porosity, microorganisms such as, Candida Albicans adhere less to the denture bases, which reduces the potential for infections (7).

In spite of, CAD/CAM-fabricated complete denture seeking to address the disadvantages associated with conventional complete denture fabrication, scientific evidences regarding physico-mechanical properties and 
monomer release from CAD/CAM fabricated prostheses are missing so far.

There is limited available data about the properties of $\mathrm{CAD} / \mathrm{CAM}$ processed denture base material. Hence, the objective of this in-vitro study was to evaluate and compare physico-mechanical properties of prepolymerized resin denture base material to conventional heat-cure acrylic resin.

\section{MATERIALS AND METHODS \\ Materials}

The materials that have been used in this study were shown in the down illustrated table 1.

Table 1: Show the studied materials used.

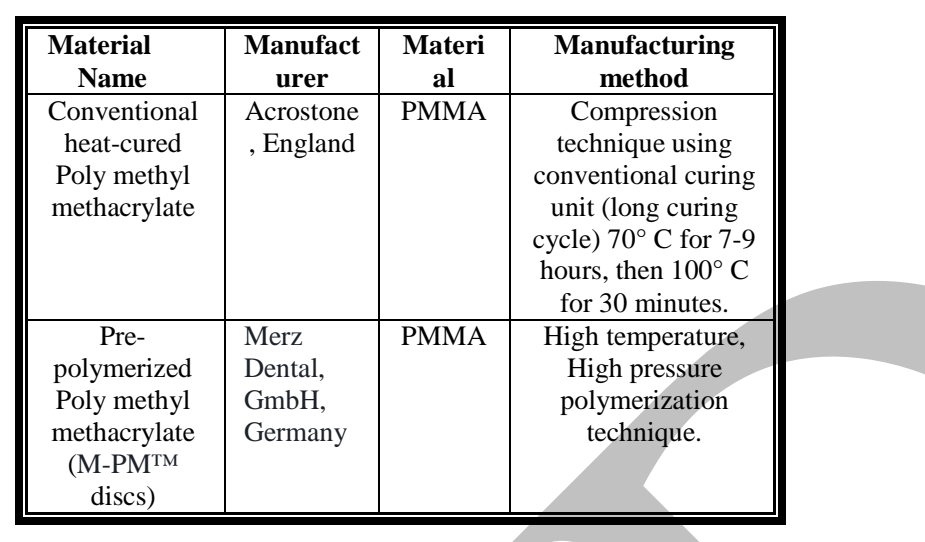

\section{Methods}

The laboratory tests that have been used to perform evaluation of some important physico-mechanical properties between the two studied materials are:

1-Impact strength test.

2-Flexural strength test.

3-Surface roughness test.

4-Quantitative analysis for estimation of residual monomer.

The sample size of the study was calculated using Larry Connors method (8) and a prospective comparative study was done. A total of 80 Specimens were prepared according to the international standards specifications for each test. The specimens were divided into two groups as the following:

Group I (control group): 40 specimens of conventional heat cure acrylic resin denture base material (16 specimens for impact strength test, 16 specimens for flexural strength test and 8 specimens for surface roughness).

Group II (study group): 40 specimens of CAD/CAM PMMA (16 specimens for impact strength test, 16 specimens for flexural strength test and 8 specimens for surface roughness).

Each group was divided into 2 sub-groups (A \& B) then was subjected to 4 different tests.

Sub-group A: 8 Specimens for each test were stored in the incubator at $37^{\circ} \mathrm{C}$ for 24 hours (called thermo-cycle zero or no thermo-cycling).

Sub-group B: To examine the effects of temperature variations, 8 specimens for each test were thermo-cycled for 500 cycles between $5^{\circ} \mathrm{C}$ and $55^{\circ} \mathrm{C}$ with a dwell time (time taken by the specimens in each bath) of 60 seconds and transfer time (time taken by the specimens to be transferred from one bath to another) of 30 seconds (9).
For surface roughness test, the same specimens (8 specimens for control group \& 8 specimens for study group) after stored in distilled water (thermo-cycle zero) and subjected to test, were thermo-cycled in thermocycling machine, then were subjected to the test again because this test is non-destructive.

For quantitative analysis for estimation of residual monomer, pieces from the fractured specimens from each sub-group of any of the previous tests were grinded into fine powder then pressed into discs in order to be used later for testing.

\section{1- Impact strength test}

Specimens Preparation: For group (I): Metallic mold having the dimensions of impact strength test specimens according to the method described in the ISO standard (ISO 179-1; 2010), (10) bar shaped of 75 mm length, $10 \mathrm{~mm}$ width, $10 \mathrm{~mm}$ thickness with notch of $2 \mathrm{~mm}$ depth at the mid span was constructed. Base plate wax was softened and poured into the mold. After hardening, the wax was removed, then a mix of dental stone was done with constant water/powder ratio of $30 \mathrm{~mL}$ of water to 100 $\mathrm{g}$ of powder. The mix was then poured in the lower half of the flask. The flask was placed on a vibrator to remove any air bubbles present in the mix. The wax specimens were placed in the stone mix before setting and they were flasked by the usual technique for denture construction. The flask was de-waxed sufficiently to remove the wax completely from the mold. Any residual wax was washed out with boiling water.

The polymer (powder) and the monomer (liquid) both were mixed 3:1 by volume according to the manufacturer's instructions in a clean glass or ceramic jar. The powder and liquid both were mixed thoroughly, the lid of the jar was closed and the mix was allowed to stand for 10-15 minutes to reach the dough consistency.

The acrylic dough was packed with slight excess and the flask was closed. Trial closure was performed to remove excess of resin material by using the Hydromatic dental press. The curing was done according to the manufacturer's instructions using conventional curing unit (long curing cycle) $70^{\circ} \mathrm{C}$ for $7-9$ hours then $100^{\circ} \mathrm{C}$ for 30 minutes. Before deflasking, the flask was bench cooled to reach room temperature (11).

For group (II): Specimens were made of prepolymerized CAD/CAM resin discs by CNC milling machine, (Figure 1 a) where a computer-aided designing software "Auto-CAD" has been used to design the specimens according to the same ISO standard method and dimensions that was described previously in group (I).

Conduct of test: All specimens were accurately mounted on the vice of the pendulum testing machine (Charpy type impact tester). The specimen was supported horizontally at its ends and it was struck by a freeswinging pendulum which was released from a fixed height. A pendulum of $15 \mathrm{~J}$ testing capacity was used. The scale reading gave the impact energy absorbed to fracture the specimen in joules when struck by a sudden blow. Then the impact strength was calculated in $\mathrm{KJ} / \mathrm{mm} 2$ as given by the following equation:(12)

Impact strength $=\frac{\mathrm{E}}{b d} \times 103$

Where:

$\mathrm{E}$ : is the impact absorbed energy in joules. 
b: is the width in millimeters of the test specimens (10mm).

$\mathrm{d}$ : is the thickness in millimeters of the test specimens $(10 \mathrm{~mm})$

\section{2- Flexural strength test}

Specimens Preparation: For group (I): Metallic mold having the dimensions of flexural strength test specimens according to the American Dental Association Specification No.12 for denture base polymer $(65 \mathrm{~mm}$ length, $10 \mathrm{~mm}$ width and $2.5 \mathrm{~mm}$ thickness) (13) was constructed. Wax specimens were fabricated and the processing was done according to the manufacturer's instructions mentioned before in impact strength test. For group (II), specimens were made with the same dimensions of the previous (group I) of flexural strength test according to the same ADA specification that has been used. CNC milling machine has been used for specimens preparation with the same procedure which was described in the impact strength test of (group II). (Figure $1 \mathrm{a}$ ).

Conduct of test: specimens were placed on supports of the universal testing machine (three-point loading). While placing the specimen on the testing device, care was taken that the central loading plunger was touching the midline of the sample. The force in Newton was applied perpendicular to the center of specimen strips and the specimen was gradually loaded at the crosshead speed of $0.5 \mathrm{~mm} / \mathrm{min}$ (3). The load was applied till maximum capacity of the three-point testing device was recorded.

The flexural strength was calculated according to the following equation: (3)

Flexural strength $(\mathrm{S})=\frac{3 \mathrm{PL}}{2 b d^{2}}(\mathrm{MPa})$

Where:

$\mathrm{P}=$ load at fracture (or load at maximum deflection).

$\mathrm{L}=$ distance between the two supporting points $(50 \mathrm{~mm})$.

$\mathrm{b}=$ width of the test specimens $(10 \mathrm{~mm})$.

$\mathrm{d}=$ thickness of specimen $(2.5 \mathrm{~mm})$.

\section{3- Surface roughness test}

Specimens Preparation: For group (I): Disk-shaped split metallic mold having the dimensions of surface roughness test specimens according to the ADA specification No.12 with $50 \mathrm{~mm}$ in diameter, $0.5 \mathrm{~mm}$ in thickness (14) was constructed with the same preparation technique that has been done in both impact and flexural strength tests.

For group (II): Specimens were made with the same dimensions and specification of (group I) using CNC milling manufacturing technique. (Figure $1 \mathrm{~b}$ ).

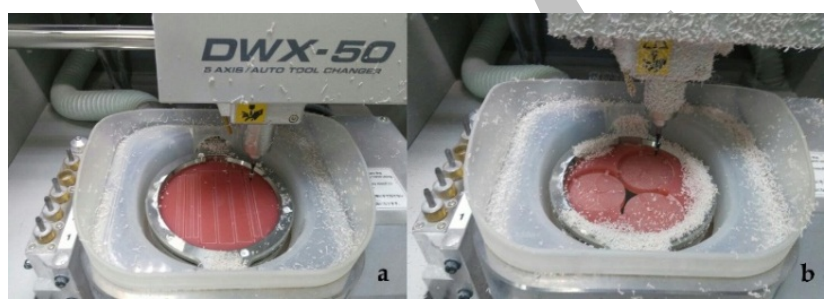

Figure 1: Showing CNC milling machining. (a) for Impact, Flexural \& (b) for Surface roughness Group II Specimens.

Conduct of test: The measurement was carried out using the "surface roughness meter". It consists of a Stylus which was mechanically drawn across the surface of the specimens by the drive unit. It also travelled perpendicular to the surface as it ascends or descends over the irregularities of the specimen, measuring value is given in unit of micrometer $(\mu \mathrm{m})$.

\section{4- Quantitative analysis for estimation of residual monomer}

Specimens Preparation: Pieces from the fractured specimens from each sub-group from control \& study groups of any of the previous tests were grinded by using a dry and clean blinder machine. Then 10mg of each samples powder was grinded finely. The yielded powder was then thoroughly mixed with ten times its bulk of pure potassium bromide $(\mathrm{KBr})$ as a base. The mixture is then pressed into discs under 5 tons for 1 minute using the mold and a hydraulic press of the apparatus. These discs were then mounted on holder and placed in lenses of the device in order to study the samples (15).

Conduct of test: The sample film was placed in the sample beam of the spectrophotometer device, then the beam was passed to the detector for final measurement, 6 scans were accomplished. The measured signal was digitized and sent to the computer where the Fourier transformation took place.

Each sample studied by this device gave us an InfraRed chart which shows peaks. Two absorbance peaks appeared, the absorbance peak of the $\mathrm{C}=\mathrm{C}$ bond from the methacrylate group at the wavelength $1640 \mathrm{~cm}-1$ and the absorbance peak of the $\mathrm{C}=\mathrm{O}$ bond from the ester group at the wavelength $1720 \mathrm{~cm}-1$ (16).

An appropriate base line was drawn, the intensity of absorption was determined by calculating the areas of peaks by the Auto-CAD software (17). The mean of three readings was recorded.

The degree of conversion was calculated by comparison of the absorbance ratio of the $\mathrm{C}=\mathrm{C}$ peak to that of the unchanging $\mathrm{C}=\mathrm{O}$ peak before and after polymerization by taking the ratio between the two absorbance. The fraction of unreacted double bonds could be calculated from the following formula: (15)

$$
\begin{aligned}
& \mathrm{DC} \%=\left[1-\frac{\{\boldsymbol{A b s}(\boldsymbol{C}=\boldsymbol{C}) / \boldsymbol{A b s}(\boldsymbol{C}=\boldsymbol{O})\} \text { Polymerized sample }}{\{\boldsymbol{A b s}(\boldsymbol{C}=\boldsymbol{C}) / \boldsymbol{A b s}(\boldsymbol{C}=\boldsymbol{O})\} \text { Monomer }}\right] * \\
& 100 \%
\end{aligned}
$$

After that the residual monomer was calculated by subtracting the obtained degree of conversion out of $100 \%$.

\section{STATISTICAL ANALYSIS}

Data were analyzed using IBM SPSS software version 20.0. (Armonk, NY: IBM Corp). Qualitative data were described using number and percent. Quantitative data were described using range (minimum and maximum), mean, standard deviation and median. The KolmogorovSmirnov test was used to verify the normality of distribution of quantitative variables. Student t-test was used for normally distributed variables. For the abnormally distributed variables Mann Whitney test was used and Wilcoxon signed ranks test was used for comparing between them. Significance of the obtained results was judged at the $5 \%$ level (18).

\section{RESULTS}

\section{1-Impact strength test}

During testing, all the specimens of the two groups fractured immediately after the first strike producing a clean fracture surface. The fracture line started from the base of the v- shape notch and extended downward. All of the fractured specimens could be re-assembled. 
Table (2 a) \& figure (2) compare the mean values of impact strength of specimens for both groups at different conditions and represent the effect of thermo-cycling on them.

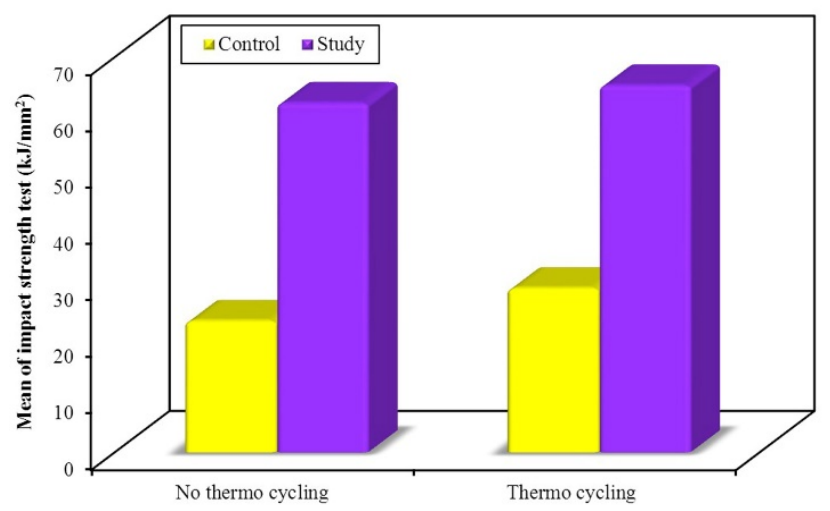

Figure 2: Showing comparison between the mean values of the two studied groups according to impact strength test in $\left(\mathrm{kJ} / \mathrm{mm}^{2}\right)$, before \& after thermo-cycling.

Table 2a: Comparison between the two studied groups according to (a) impact strength test

\begin{tabular}{|c|c|c|c|c|}
\hline \multirow{5}{*}{ 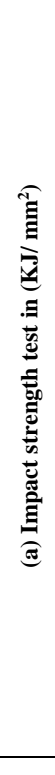 } & $\begin{array}{l}\text { Subgroups } \\
\text { A \& B }\end{array}$ & $\begin{array}{c}\text { Group I } \\
\text { Control } \\
(\mathbf{n}=\mathbf{8})\end{array}$ & $\begin{array}{c}\text { Group II } \\
\text { Study } \\
(n=8)\end{array}$ & U (P) \\
\hline & $\begin{array}{l}\text { No thermocycling } \\
\text { Min. - Max. } \\
\text { Mean } \pm \text { SD. } \\
\text { Median }\end{array}$ & $\begin{array}{c}11.0-35.0 \\
23.25 \pm 7.76 \\
25.0\end{array}$ & $\begin{array}{c}40.0- \\
85.0 \\
\\
61.88 \pm \\
17.10 \\
65.0\end{array}$ & $\begin{array}{c}0.00^{*} \\
\left(0.001^{*}\right)\end{array}$ \\
\hline & $\%$ of Change & $\uparrow 16$ & & \\
\hline & $\begin{array}{c}\text { Thermocycling } \\
\text { Min. - Max. } \\
\text { Mean } \pm \text { SD. } \\
\text { Median }\end{array}$ & $\begin{array}{c}20.0-35.0 \\
29.06 \pm 5.33 \\
30.0\end{array}$ & $\begin{array}{c}45.0- \\
90.0 \\
\\
65.0 \pm \\
16.26 \\
67.50\end{array}$ & $\begin{array}{c}0.00^{*} \\
\left(0.001^{*}\right)\end{array}$ \\
\hline & $\%$ of Change & $\uparrow 12$ & 68 & \\
\hline & $\mathbf{U}(\mathbf{P})$ & $\begin{array}{c}17.50 \\
(0.120)\end{array}$ & $\begin{array}{c}27.50 \\
(0.631)\end{array}$ & \\
\hline
\end{tabular}

- Mann Whitney test was used for comparing between the two studied groups at both conditions. It revealed that thermo-cycling had a non-significant difference on the impact strength of both group (I) \& group (II) with $(\mathrm{U}=17.50)(\mathrm{P}=0.120) \&(\mathrm{U}=27.50)(\mathrm{P}=0.631)$ respectively.

- In general, the mean values of impact strength of CAD/CAM PMMA were higher than of conventional PMMA.

- At zero thermo-cycling, the results were analyzed and compared between the two studied groups which revealed a statistical significant increase by $166.15 \%$ in impact strength for group (II) when compared to group (I), where $(\mathrm{U}=0.00)(\mathrm{P}=0.001)$.

- After thermo-cycling, also there was a statistical significant higher impact strength of group (II) than group (I) by $123.68 \%$ at $5 \%$ level where $(\mathrm{U}=0.00)(\mathrm{P}=0.001)$.

\section{2-Flexural strength test}

During testing, the acrylic specimens for (Group I \& Group II) showed gradual bending then finally broke in clean cut. In all of the specimens, the fracture line was sharp and located nearly at the center of the specimens where the load was applied. All of the fractured specimens could be re-assembled.

Table (2 b) \& figure (3) show the mean flexural strength values for both studied groups (i.e. Group I and Group II) in both conditions (i.e. zero thermo-cycling and after thermo-cycling).

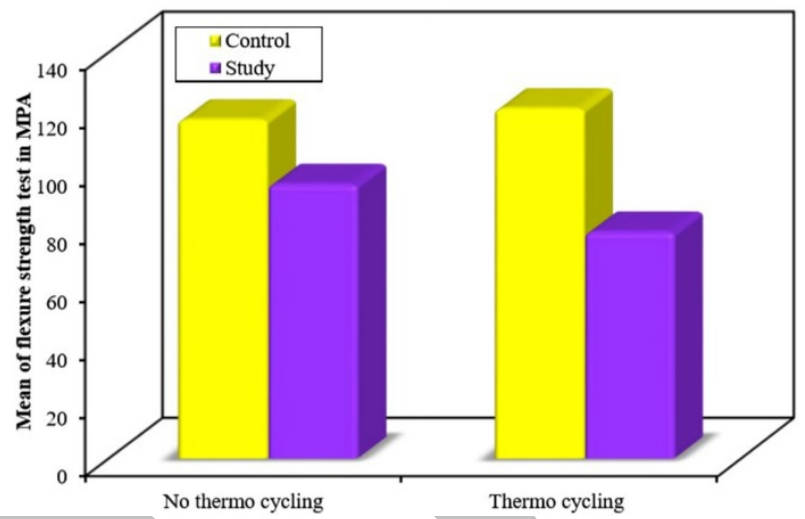

Figure 3: Showing comparison between the mean values of the two studied groups according to flexural strength test in (MPa), before \& after thermo-cycling.

- According to Student t-test, when comparing the two groups we found that there was no statistically difference in flexural strength of conventional PMMA after thermocycling, where $(\mathrm{t}=0.340)(\mathrm{P}=0.739)$. While for CAD/CAM PMMA, thermo-cycling statistically decreased its flexural strength, with $(\mathrm{t}=3.746)(\mathrm{P}=0.002)$.

- In addition, we found that the CAD/CAM PMMA denture base material has a statistical significant reduction of flexural strength when compared to conventional denture base material by $19.01 \%$ \& $35.22 \%$ in both (before and after thermo-cycling) respectively with significant different $(\mathrm{t}=2.452)(\mathrm{p}=0.028)$ at zero thermo-cycling and $(\mathrm{t}=5.352)(\mathrm{P}=<0.001)$ after thermo-cycling.

Table 2 b: Comparison between the two studied groups according (b) flexure strength test, before $\&$ after thermo-cycling.

\begin{tabular}{|c|c|c|c|c|}
\hline \multirow{6}{*}{ 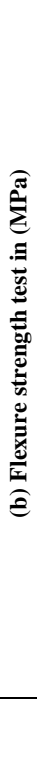 } & $\begin{array}{l}\text { Subgroups } \\
\text { A \& B }\end{array}$ & $\begin{array}{c}\text { Group I } \\
\text { Control }(n=8)\end{array}$ & $\begin{array}{c}\text { Group II } \\
\text { Study }(n=8)\end{array}$ & $t(P)$ \\
\hline & $\begin{array}{l}\text { No thermocycling } \\
\text { Min. - Max. } \\
\text { Mean } \pm \text { SD. } \\
\text { Median }\end{array}$ & $\begin{array}{c}81.55-166.64 \\
116.79 \pm 24.95 \\
114.20\end{array}$ & $\begin{array}{c}83.10-100.0 \\
94.58 \pm 5.75 \\
95.85\end{array}$ & $\begin{array}{c}2452^{*} \\
\left(0.028^{*}\right)\end{array}$ \\
\hline & $\%$ of Change & \multicolumn{2}{|c|}{$\downarrow 19.01 \%$} & \\
\hline & $\begin{array}{l}\text { Thermocycling } \\
\text { Min. - Max. } \\
\text { Mean } \pm \text { SD. } \\
\text { Median }\end{array}$ & $\begin{array}{c}84.70-147.20 \\
120.61 \pm 19.56 \\
121.10\end{array}$ & $\begin{array}{c}64.50-93.80 \\
78.12 \pm 11.02 \\
76.35\end{array}$ & $\begin{array}{c}5.352^{*} \\
\left(<0.001^{*}\right)\end{array}$ \\
\hline & $\%$ of Change & \multicolumn{2}{|c|}{$\downarrow 35.22 \%$} & \\
\hline & $t(P)$ & $\begin{array}{c}0.340 \\
(0.739)\end{array}$ & $\begin{array}{c}3.746^{*} \\
\left(0.002^{*}\right)\end{array}$ & \\
\hline
\end{tabular}


U, p: U and p values for Mann Whitney test for comparing between two groups.

$\mathrm{t}, \mathrm{p}$ : $\mathrm{t}$ and $\mathrm{p}$ values for Student t-test for comparing between two groups.

*: Statistically significant at $\mathrm{p} \leq 0.05$.

\section{3- Surface roughness test}

Table 3(a) \& figure (4) represent the comparison of the mean values of surface roughness for both studied groups I \& II at both conditions before and after thermo-cycling.

Table 3(a): Comparison between the two studied groups according to (a) surface roughness meter test

\begin{tabular}{|c|c|c|c|c|}
\hline \multirow{6}{*}{ 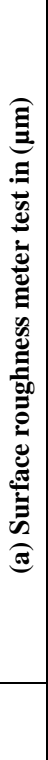 } & $\begin{array}{l}\text { Subgroups } \\
\text { A \& B }\end{array}$ & $\begin{array}{c}\text { Group I } \\
\text { Control } \\
(\mathbf{n}=\mathbf{8})\end{array}$ & $\begin{array}{c}\text { Group II } \\
\text { Study } \\
(\mathbf{n}=\mathbf{8})\end{array}$ & $\mathbf{U}(\mathbf{P})$ \\
\hline & $\begin{array}{c}\text { No thermocycling } \\
\text { Min. - Max. } \\
\text { Mean } \pm \text { SD. } \\
\text { Median }\end{array}$ & $\begin{array}{c}0.14-0.82 \\
0.46 \pm 0.27 \\
0.48\end{array}$ & $\begin{array}{c}0.16-0.43 \\
0.27 \pm 0.10 \\
0.24\end{array}$ & $\begin{array}{c}22.0 \\
(0.294)\end{array}$ \\
\hline & \% of Change & \multicolumn{2}{|c|}{$\downarrow 41.30 \%$} & \\
\hline & $\begin{array}{c}\text { Thermocycling } \\
\text { Min. - Max. } \\
\text { Mean } \pm \text { SD. } \\
\text { Median }\end{array}$ & $\begin{array}{c}0.13-2.02 \\
0.85 \pm 0.65 \\
0.77\end{array}$ & $\begin{array}{c}0.06-0.46 \\
0.27 \pm 0.15 \\
0.26\end{array}$ & $\begin{array}{c}13.0 \\
\left(0.046^{*}\right)\end{array}$ \\
\hline & \% of Change & \multicolumn{2}{|c|}{$\downarrow 68.24 \%$} & \\
\hline & $\mathrm{Z}(\mathbf{P})$ & $\begin{array}{c}2.100 \\
\left(0.036^{*}\right)\end{array}$ & $0.00(1.000)$ & \\
\hline
\end{tabular}

$\mathrm{U}, \mathrm{p}$ : $\mathrm{U}$ and $\mathrm{p}$ values for Mann Whitney test for comparing between two groups.

$\mathrm{t}, \mathrm{p}: \mathrm{t}$ and $\mathrm{p}$ values for Student $\mathrm{t}$-test for comparing between two groups. $\mathrm{Z}, \mathrm{p}: \mathrm{Z}$ and $\mathrm{p}$ values for Wilcoxon signed ranks test for comparing between two groups.

*: Statistically significant at $\mathrm{p} \leq 0.05$.

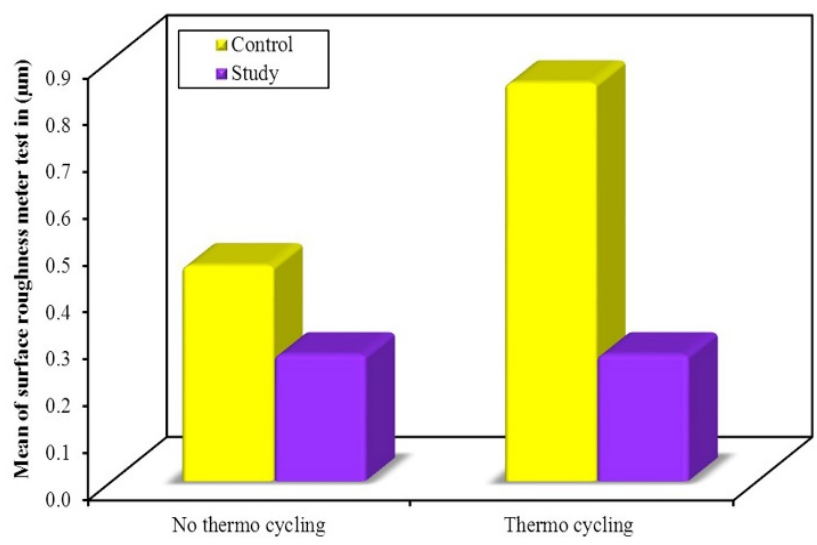

Figure 4: Showing comparison between the mean values of the two studied groups according to surface roughness meter test in $(\mu \mathrm{m})$, before \& after thermo-cycling.

On analyzing the effect of thermo-cycling on both groups using Wilcoxon signed ranks test, we found that group (I) had a statistical significant increase after thermocycling by $84.78 \%$ with $(\mathrm{Z}=2.100)(\mathrm{P}=0.036)$. For group (II) there was a statistically non-significant difference at $5 \%$ level where $(\mathrm{Z}=0.00)(\mathrm{p}=1.000)$.

The results were analyzed using Mann Whitney test to compare between both groups, which revealed that before thermo-cycling, there was a slight reduction in surface roughness values in group (II) when compared to group (I) by $41.30 \%$ where $(\mathrm{U}=22.0)(\mathrm{P}=0.294)$.

After thermo-cycling, group (II) showed a statistical significant reduction by $68.24 \%$ when compared to group (I) with $(\mathrm{U}=13.0)(\mathrm{P}=0.046)$.

\section{4- Quantitative analysis for estimation of residual monomer}

Table (3 b) \& figure (5) represent the comparison between the two groups both before $\&$ after thermo-cycling. The results were analyzed using Student t-test which revealed that for both groups (I) \& (II), there was a significant decrease in residual monomer after thermo-cycling with $(\mathrm{t}=62.738) \quad(\mathrm{P}=<0.001) \quad \& \quad(\mathrm{t}=82.488) \quad(\mathrm{P}=<0.001)$ respectively.

Table 3(b):Comparison between the two studied groups according residual monomer test, before \& after thermo-cycling.

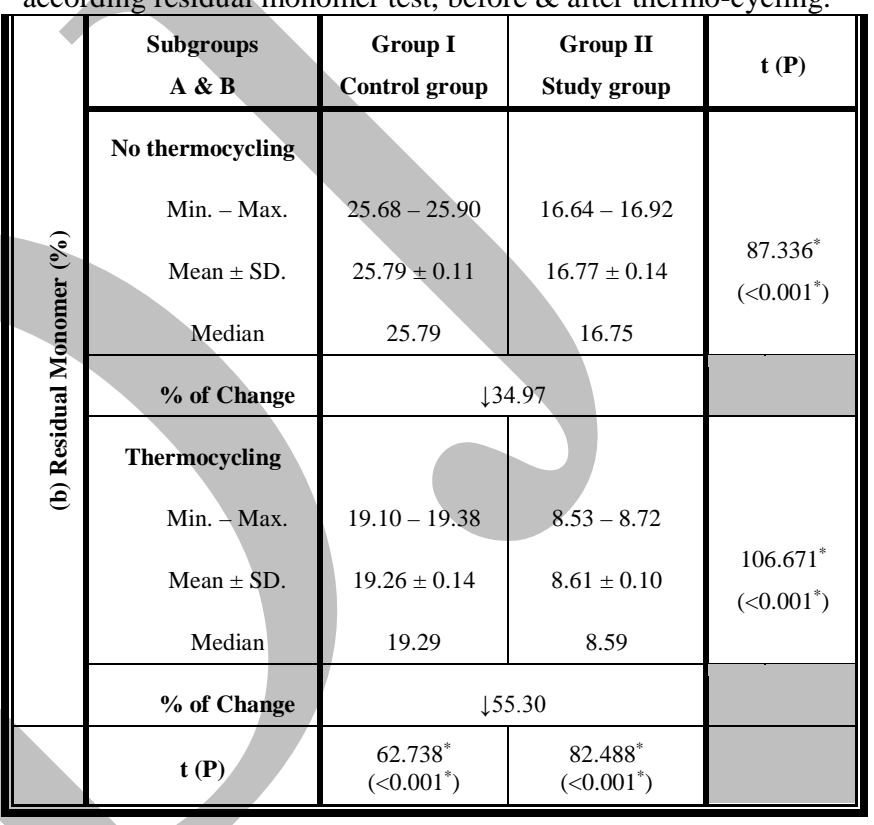

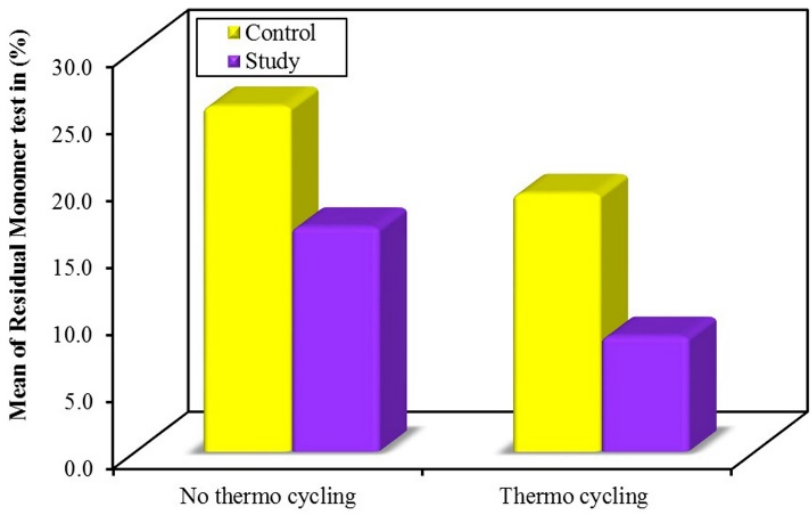

Figure 5: Showing comparison between the mean values of the two studied groups according to residual monomer test in (\%), before \& after thermo-cycling.

Additionally, CAD/CAM PMMA showed a high statistical significant reduction in the amount of residual monomer when compared to conventional PMMA by (34.97\% \& 55.30\%) with $(\mathrm{t}=87.336) \quad(\mathrm{P}=<0.001) \quad$ \& $(\mathrm{t}=106.671)(\mathrm{P}=<0.001)$ before and after thermo-cycling respectively.

\section{5- On correlation between impact and flexural strength tests}


The data of impact and flexural strength tests were correlated using Spearman coefficient test, which revealed a statistical significant negative correlation between impact and flexural strength of group (II) after thermo-cycling, as shown in (figure 6).

It means that, for CAD/CAM PMMA after thermal changes, with the increase in impact strength there was a statistical significant decrease in flexural strength with $(\mathrm{P}$ $=0.043)$ (rs = -0.701). Where: rs: Spearman coefficient, *: Statistical significant at $\mathrm{p} \leq 0.05$.

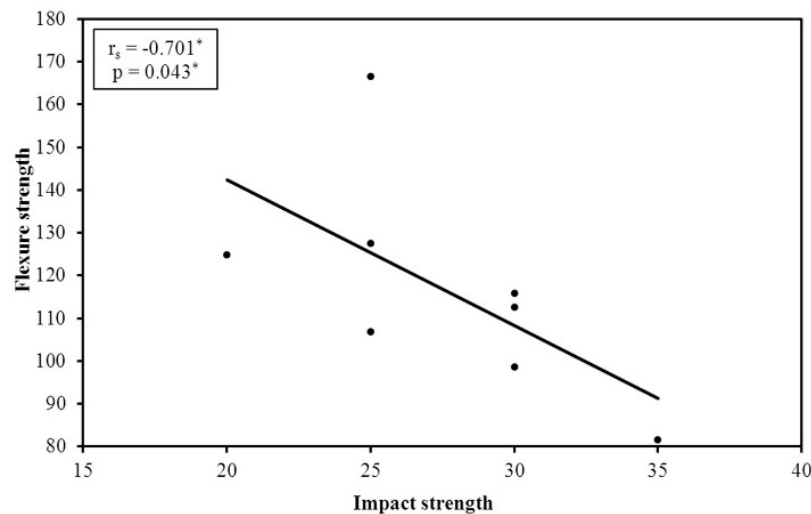

Figure 6: Showing correlation between impact strength test with flexural strength test of the study group (Group II) after thermocycling.

\section{DISCUSSION}

The presence of unreacted methacrylate monomer in denture base resins is undesired because it impedes the resin's mechanical properties (19) and also compromises the product's biocompatibility as it leaches into the surrounding tissues and saliva (20). This released monomer had been suspected of being responsible for allergic or cytotoxic reactions of denture base materials (21).

CAD/CAM-fabricated dentures are hypothesized to have enhanced material-specific properties because the denture base is milled from poly methyl methacrylate (PMMA) pucks that have been polymerized under high temperature and pressure (22), which is at fifty times the conventional processing pressure (23). The high pressure promotes the formation of longer polymer chains (24) and therefore when compared to a conventional processed denture, leads to a higher degree of monomer conversion with lower values of residual monomer (25).

Although the hypothesis that CAD/CAMfabricated dentures should therefore release less monomer (22) is conclusive, scientific evidences regarding physico-mechanical properties and monomer release from CAD/CAM fabricated prostheses are missing so far (25).

There are limited reports in the literature evaluating the CAD/CAM as a denture base material. So, this study was conducted in order to evaluate the most important physico-mechanical properties of CAD/CAM PMMA. Four tests were conducted: impact strength test, flexural strength test, surface roughness test \& analysis of residual monomer.

Impact strength is an important property for denture base materials which have tendency to fracture if accidentally dropped onto a hard surface (10).
In our study, when comparing impact strength mean values of specimens for both groups I \& II at different conditions and represent the effect of thermocycling on them, our finding was agreed with AlAmeer (26) in 2012, who found that the impact strength of PMMA-based heat cure acrylic resin was not significantly changed by thermo-cycling.

Also, we found that CAD/CAM PMMA showed a statistical significant higher impact strength than conventional PMMA in both situations (before \& after thermo-cycling) by $166.15 \%$ \& $123.68 \%$ respectively.

Our results could be attributed to the high-pressure polymerization of CAD/CAM specimens. This result was consistent with previous study by Arita et al. (27) in 2008, who reported that the polymerization under pressure increased the average molecular weight and the polymerization rates of MMA, which in turn enhances impact strength.

Flexural strength is an important parameter that can reflect the ability of a denture base material to withstand functional masticatory forces.

For group (II), thermo-cycling statistically decreased the flexural strength, which might be explained by additional polymerization as a result of increased temperature. This enhances the degree of conversion reducing the monomer content which acts as a plasticizer, resulting in a less resilient polymer, as Gungor et al. (28) in 2017 reported.

When comparing (group I \& group II) in our study, the CAD/CAM PMMA flexural strength was significantly lower than the conventional PMMA at both conditions (zero thermo-cycle \& after thermocycling) by $33.11 \%$ \& 20.52\% respectively.

In 2013, Murakami et al. (24) agreed with our findings as he stated that polymerization under a high pressure reduced the monomer contents which act as a plasticizer, which in turn increases the toughness of the PMMA, while decreasing the yield strength, flexural strength and the elastic modulus.

Regarding surface roughness, several studies have demonstrated that rough acrylic resin surfaces are significantly more prone to bacterial accumulation and plaque formation than smooth surfaces (29).

Our result revealed an increase in surface roughness of conventional PMMA specimens after artificial aging, which was consistent with Finoti et al. (30) in 2012, who explained that by the absorption of water which acts as a plasticizer, altering the mechanical properties of the material such as surface hardness and decreasing its wear resistance resulting in increased surface roughness.

In comparing both groups (I \& II) in our study, CAD/CAM PMMA showed decreased surface roughness values both before \& after thermo-cycling but the statistical significant reduction was after thermo-cycling, which was $68.24 \%$ less than conventional PMMA, where $(\mathrm{U}=13.0)(\mathrm{P}=0.046)$.

In 2016, Roscaa et al. (31) was consistent with our result, as he stated that polymerization under standardized conditions, high pressure and high temperature, of the CAD/CAM materials result in a higher degree of conversion and less residual monomer in the material. Thus, the amount of residual monomer of free radicals is very low or even 
insufficient to allow co-polymerization and these materials present a low surface energy (wettability) and resistance to surface modification by different chemical treatments.

Considering the residual monomer, in order to increase the biocompatibility of denture bases, it was important in our study to analyze the amount of residual monomer before and after thermo-cycling for both studied groups.

On analyzing the effect of thermo-cycling on the amount of residual monomer, Milena et al. (32) in 2011 agreed with our result. He stated that after additional polymerization in a hot water bath, a significant reduction in the amount of residual monomer in the samples was observed, which agrees with the results published in literatures.

In our study CAD/CAM PMMA showed high significant reduction of residual monomer when compared to conventional PMMA by $34.97 \%$ before thermo-cycling.

After thermo-cycling, the amount of residual monomer of CAD/CAM PMMA was $8.59 \%$, which was highly significant less than of conventional PMMA by $55.30 \%$.

Our result may be due to the polymerization under high temperature high pressure conditions of CAD/CAM specimens as stated by Tang et al. (33) in 2014, who described that such polymerization process results in polymers that exhibit a significant (even dramatic) decrease in monomer release.

In 2017, Steinmassl et al. (25) also agreed, as he showed in his study that CAD/CAM dentures released very little monomer. However, he advised enhancing the manually fabricated dentures by water bath longtime heat-polymerization.

In correlation between impact strength and flexural strength, the Spearman coefficient was performed. It revealed that there was a negative correlation $(p=0.043)$ between impact strength and flexural strength of CAD/CAM PMMA. It means that, with increasing of impact strength values of the material, lower flexural strength values were detected.

Our result was supported by Murakami et al. (24) in 2013, who concluded that, besides the increase in fracture resistance, the high pressure during the polymerization process decreased the elastic modulus, the yield, and the maximum flexural strength of the PMMA-based heat curing resin.

The results of our study may increase the understanding of the effect of the high-pressure polymerization on the mechanical properties of the PMMA-based heat-curing denture base resin and lead to further developments of this polymerization method.

\section{CONCLUSION}

Within the limitations of this study, it could be concluded that:

1. In general, CAD/CAM PMMA had a statistically significant higher impact strength when compared to conventional PMMA both before and after thermo-cycling.
2. The CAD/CAM PMMA flexural strength was significantly lower than the conventional PMMA both before and after thermo-cycling.

3. CAD/CAM PMMA showed decreased surface roughness values than conventional PMMA, but the statistically significant reduction was after thermo-cycling.

4. Residual monomer of CAD/CAM PMMA was statistically significantly lower than conventional PMMA at both before and after thermo-cycling.

\section{CONFLICT OF INTEREST}

The authors declare that they have no conflicts of interest.

\section{REFERENCES}

1. Chand P, Patel CB, Singh BP, Singh RD, Singh K. Mechanical properties of denture base resins: An evaluation. Indian J Dent Res. 2011;22:180.

2. Darber UR, Guggett R, Harrison A. Denture fracture A survey. Br Dent J. 1994;176:342-5.

3. Kohli S, Bhatia S. Flexural properties of polyamide versus injection-molded poly methyl methacrylate denture base materials. Eur J Prosthodont. 2013;1:56-60.

4. Doğan OM, Bolayır G, Keskin S, Doğan A, Bek B. The evaluation of some flexural properties of a denture base resin reinforced with various aesthetic fibers. J Mater Sci Mater Med. 2008;19:2343-9.

5. Miyazaki T, Hotta Y, Kunii J, Kuriyama S, Tamaki Y. A review of dental CAD/CAM: current status and future perspectives from 20 years of experience. Dent Mater J. 2009;28:44-56.

6. Kattadiyil MT, Goodacre CJ. CAD/CAM technology: application to complete dentures. Loma Linda Univ Dent 2012; 23: 16-23.

7. Wiley J. Clinical Application of Digital Dental technology. USA: John Wiley \& Sons, Inc.; 2015. 108-10.

8. Daniel W. Biostatistics. A foundation for analysis in the health science. 6th ed. NY: John Wiley and sons, Inc; 1995.

9. Rossomando KJ, Wendt SL. Thermocycling and dwell times in microleakage evaluation for bonded restorations. Dent Mater 1995; 11: 47-51.

10. ISO 179-2:1997, Plastics - Determination of Charpy impact properties - Part 2: Instrumented impact test, ISO/TC 61/SC 2nd ed. Switzerland: International Standards Organization, 2010.

11. Rahn AO. Heartwell CM. Textbook of complete dentures. Laboratory procedures. 5th ed. USA: Williams \& Wilkins,1993:375-84.

12. Abdulwahhab SS. High-impact strength acrylic denture base material processed by autoclave. J Prosthodont Res. 2013;57:288-93.

13. Revised American Dental Association Specification no.12 for denture base polymers. J Am Dent Assoc 1975; 90: 451-8.

14. Célia M, Morgana N, Machado C. Surface roughness of acrylic resins processed by microwave energy and polished by mechanical and chemical process. Braz J Oral Sci. 2006;5:977-981.

15. Al-Ali AA, Sheet OA, Taqa AA. The Effect of Different Curing Techniques on the Degree of Bond Conversion for Different Types of Acrylic Resin Materials. Al-Rafidain Dent J. 2013;13:351-7. 
16. He L, Liang J, Zhao X, Li W, Luo H. Preparation and comparative evaluation of well-defined fluorinated acrylic copolymer latex and solution for ancient stone protection. Progr Org Coat. 2010;69:352-8.

17. Nomoto R, Asada M, Mccabe JF, Hirano S. Light exposure required for optimum conversion of light activated resin systems. Dent Mater. 2006;22:1135-42.

18. Kotz S, Balakrishnan N, Read CB, Vidakovic B. Encyclopedia of statistical sciences. 2nd ed. Hoboken, New Jersey: Wiley-Interscience; 2006.

19. Akin H, Tugut F, Polat ZA. Vitro comparison of the cytotoxicity and water sorption of two different denture base systems. J Prosthodont. 2015;24:152-5.

20. Matsuo H, Suenaga H, Takahashi M, Suzuki O, Sasaki K, Takahashi N. Deterioration of poly methyl methacrylate dentures in the oral cavity. Dent Mater J. 2015;34:234-9.

21. Rashid H, Sheikh Z, Vohra F. Allergic effects of the residual monomer used in denture base acrylic resins. Eur J Dent. 2015;9:614-9.

22. Infante L, Yilmaz B. Fabricating complete dentures with CAD/CAM technology. J Prosthet Dent. 2014;111:351-5.

23. Kattadiyil T, Goodacre J. CAD/CAM technology: application to complete dentures. Loma Linda Univ Dent. 2012;23:16-23.

24. Murakami N, Wakabayashi N, Matsushima R, Kishida A, Igarashi Y. Effect of high-pressure polymerization on mechanical properties of PMMA denture base resin. J Mech Behav Biomed Mater. 2013;20:98-104

25. Steinmassl PA, Wiedemair V, Huck CH, Klaunzer F, Steinmassl O, Grunert I, et al. Do CAD/CAM dentures really release less monomer than conventional dentures? Clin Oral Invest. 2017;21:1697-705.

26. Al-Ameer SS. Effect of thermocycling on some mechanical properties of polyamide hypoallergenic denture base material (comparative study). Scientific J. 2012; 24: 25-30.

27. Arita T, Kayama Y, Ohno K, Tsujii Y, Fukuda T. High pressure atom transfer radical polymerization of methyl methacrylate for well-defined ultrahigh molecular-weight polymers. Polymer. 2008;49:2426-9.

28. Gungor H, Gundogdu M, Alkurt M, Duymus Z. Effect of polymerization cycles on flexural strengths and microhardness of different denture base materials. Dent Mater J. 2017;36:168-73.

29. Morgan TD, Wilson M. The effects of surface roughness and type of denture acrylic on biofilm formation by Streptococcus oralis in constant depth film fermentor. J Appl Microbiol. 2001;91:47-53.
30. Finoti LS, Machado AL, Chaves CA, Pavarina AC, Vergani CE. Effect of long-term water immersion on the fracture toughness of denture base and reline resins. Gerodontology. 2012; 29:858-64.

31. Roscaa B, Ramalho S, Fernandes J, Portugal J. Reparability of two different CAD/CAM polymer materials using a light-cured composite and universal adhesives. Rev Port Estomatol Med Dent Cir Maxillofac. 2016;57:189-96.

32. Milena K, Nebojša K, Ljubisa N, Vesna N, Stevo N, Ivan $\mathrm{K}$, et al. The influence of residual monomer reduction in quality of resin materials stomatoprotetskih. Hem Ind. 2011;65:171-77.

33. Tang M, Nguyen J, Sadoun M, Dorin Ruse N. HPLC Analysis of Monomer Release from Conventionally and High Temperature High-Pressure Polymerised Urethane Dimethacrylate Intended for Biomedical Applications. J Chromatograph Separat Techniq. 2014;5:227. 